\title{
An improvement to the transesterification process by the use of co-solvents to produce biodiesel
}

\author{
José M. Encinar ${ }^{\mathrm{a}}$, Ana Pardal ${ }^{\mathrm{b}}$, Nuria Sánchez ${ }^{\mathrm{a}, *}$ \\ ${ }^{a}$ Department of Chemical Engineering and Physical Chemistry, University of Extremadura, Avenida de Elvas s/n, 06006 Badajoz, Spain \\ ${ }^{\mathrm{b}}$ Department of Technologies and Applied Sciences, ESAB, IPBeja, Rua Pedro Soares s/n, 7800 Beja, Portugal
}

\section{H I G H L I G H T S}

- The presence of co-solvents facilitates the reaction of transesterification.

- High yield and fast reaction could be obtained at relatively low temperature.

- The optimum conditions led to biodiesel with $98 \%$ ester content.

- Transesterification kinetics was described by a pseudo first order kinetic model.

\section{A R T I C L E I N F O}

\section{Article history:}

Received 4 September 2015

Received in revised form 22 October 2015

Accepted 27 October 2015

Available online 2 November 2015

\section{Keywords:}

\section{Biodiese}

Transesterification

Rapeseed oil

Co-solvent

Cetane number

Kinetic and thermodynamic analysis

\begin{abstract}
A B S T R A C T
The use of several co-solvents such as acetone, diethyl ether (DEE), dibutyl ether (diBE), tert-butyl methyl ether (tBME), diisopropyl ether (diIPE) and tetrahydrofuran (THF) could produce important improvement to the transesterification process. The influence of catalyst concentration $(\mathrm{KOH})$, methanol/oil molar ratio, methanol/co-solvent molar ratio, co-solvent type, catalyst type, agitation rate and reaction temperature was investigated. The process was mainly affected when DEE, tBME and THF were used, achieving biodiesel with high methyl ester content. The maximum methyl ester content was 97-98\%, when 9:1 as methanol/oil molar ratio, $0.7 \mathrm{wt} \% \mathrm{KOH}, 1: 1$ as co-solvent/methanol molar ratio, $700 \mathrm{rpm}$ and $30{ }^{\circ} \mathrm{C}$ were used. In addition, fuel properties of the biodiesel were determined and its cetane number was estimated based on several correlations proposed in literature. The kinetics of the reaction was also analyzed by the determination of the rate constants. Arrhenius and Eyring Polanyi equations were used to find out the activation energy and the variations of the enthalpy and entropy of the system.
\end{abstract}

() 2015 Elsevier Ltd. All rights reserved.

\section{Introduction}

Globally, the awareness of energy issues and environmental problems associated with burning fossil fuels has encouraged many researchers to investigate the possibility of using alternative sources of energy instead of mineral oil and its derivatives. Among them, biodiesel seems very interesting and can replace diesel fuel in many different applications such as boilers and internal combustion engines without major modifications and just small decrease in performance. As is known, according to the directive $2003 / 30 / E C$, biodiesel is defined as "a methyl-ester produced from vegetable or animal oil, of diesel quality, to be used as biofuel" [1].

Blending of biodiesel with diesel fuel increases engine efficiency and contributes to rural development. In addition, biodiesel offers

\footnotetext{
* Corresponding author. Tel.: +34 924289672.

E-mail address: nuriass@unex.es (N. Sánchez).
}

many advantages in environmental, technical, economic and social aspects, with respect to diesel: it has renewable and biodegradable character; it is non-flammable and non-toxic; it does not contain sulphur and aromatics compounds; it has high cetane number, good lubricity, higher flash point and it reduces dependence on imported oil. On the other hand, biodiesel does not produce greenhouse effects, since only there is a small net contribution of carbon dioxide $\left(\mathrm{CO}_{2}\right)$ when the whole life-cycle is considered (including cultivation, production of oil and conversion to biodiesel) [2,3].

Biodiesel also shows higher density and viscosity than diesel, and could show freezing problems at low temperatures. These can be some of the disadvantages in biodiesel use, besides an increase in fuel consumption and nitrogen oxide emissions [4,5]. However, the use of pure biodiesel allows to reduce the total unburned hydrocarbons ( $-67 \%)$, $\mathrm{CO}$ emissions $(-48 \%), \mathrm{CO}_{2}$ generation $(-79 \%)$, particulate matter emissions $(-47 \%), \mathrm{SO}_{x}$ formation $(-100 \%)$, polycyclic aromatic hydrocarbons (PAHs) generation $(-80 \%)$ and nitrated PAHs formation $(-90 \%)[6,7]$ 
Raw material cost is usually the most important factor in biodiesel final price. Edible and non-edible oils are used to produce this fuel. Also other products such as algae or biomass waste have been suggested as suitable raw materials [8]. In general, the synthesis of biodiesel is carried out by the transesterification reaction. This reaction generates fatty acid alkyl esters and glycerol and, in order to achieve an adequate rate, catalyst should be used [9]. Homogeneous (alkaline and acid) and heterogeneous catalysts can be utilized, although homogeneous alkaline catalysts $(\mathrm{NaOH}$, $\mathrm{CH}_{3} \mathrm{ONa}$ and $\mathrm{KOH}$ ) are the most active. Nevertheless, this type of catalysts requires an expensive separation with high consumption of energy and large generation of wastewater. Moreover, the formation of soap by reaction between the catalyst and free fatty acids of the feedstock could be possible. So, many researchers have focused on how to decrease the severity of the reaction conditions $[6,10]$.

In the transesterification reaction, methanol and oil phases are insoluble. Hence the mass transfer between both phases affects to the reaction rate initially. A rise in reaction temperature can improve the solubility, although this process implies higher energy consumption and just an increase of $2-3 \mathrm{wt} \%$ of the solubility with temperature increases of $10^{\circ} \mathrm{C}$ [11]. Therefore, additional ways to enhance the system solubility, such as the use of co-solvents, have been researched [12-18]. Co-solvents can increase the mutual solubility of methanol and vegetable oil at lower reaction temperatures, increase the reaction rate and they are usually easy to be recovered and reused.

The use of a mixture of methanol and tetrahydrofuran led to a reaction rate 15 times higher than the reaction rate with methanol at low temperature [13]. Tetrahydrofuran was also used to obtain biodiesel from Jatropha curcas seed oil; then, $40^{\circ} \mathrm{C}$ was the optimal reaction temperature [14]. Acetone as co-solvent was suitable to produce biodiesel at room temperature by using $4.5: 1$ as acetone/methanol molar ratio, $1 \mathrm{wt} \% \mathrm{KOH}$ and less than $30 \mathrm{~min}$ as reaction time [15]. Acetone was also used to obtain $98 \%$ conversion at $40{ }^{\circ} \mathrm{C}$, with $20 \mathrm{wt} \%$ acetone, $5: 1 \mathrm{molar}$ ratio of methanol/oil, $1 \mathrm{wt}$ $\% \mathrm{KOH}$ and $30 \mathrm{~min}$ as reaction time [16]. The transesterification of cotton seed oil into biodiesel was carried out using diethyl ether, dichlorobenzene or acetone as co-solvent. The optimal reaction temperature was $55^{\circ} \mathrm{C}$ for $10 \mathrm{~min}$ with $0.75 \mathrm{wt} \% \mathrm{KOH}$ as catalyst concentration [17]. The ethers are usually good as co-solvent because contain the balance of polar and nonpolar entities required to lower the interfacial surface tension between methanol and vegetable oil [18]. In some cases, the use of a co-solvent allowed the production of biodiesel from grain based feedstock, waste cooking oils and animal fats; although co-solvents must be completely removed from glycerol and biodiesel phase, because of its possible hazard and toxicity [19].

In most of previous works, only one compound was evaluated as co-solvent. For this reason the aim of this work is the study of several co-solvents in the transesterification of rapeseed oil, using methanol as alcohol. A wide overview has been obtained in this work since five compounds were used as co-solvent and whole reaction conditions were assayed. Catalyst type and concentration, reaction temperature, methanol/oil molar ratio, co-solvent type, co-solvent/methanol molar ratio and agitation rate were studied. In addition, a kinetic and thermodynamic analysis was carried out and fuel properties were determined.

\section{Materials and methods}

\subsection{Materials}

Rapeseed oil was provided by Research Center "La OrdenValdesequera" (Badajoz-Spain) Section of Non-Food Crops. It was characterized and its fatty acid profile and properties are shown in Table 1. Potassium hydroxide, $85 \%(\mathrm{KOH})$ (pellets GR for analysis), was supplied by Merck. Lithium hydroxide 1-hidrate, 99\% $\left(\mathrm{LiOH} \cdot \mathrm{H}_{2} \mathrm{O}\right)$, barium hydroxide 8 -hydrate, $97 \%\left(\mathrm{Ba}(\mathrm{OH})_{2} \cdot 8 \mathrm{H}_{2} \mathrm{O}\right)$, aluminium chloride anhydrous, $98 \%\left(\mathrm{AlCl}_{3}\right)$, zinc chloride, $97 \%\left(\mathrm{ZnCl}_{2}\right)$ and boron trifluoride, $14 \%$ in methanol $\left(\mathrm{CH}_{4} \mathrm{BF}_{3} \mathrm{O}\right)$, were purchased from Panreac. p-toluenesulfonic acid monohydrate, 98.5\% (p$\mathrm{TsOH} \cdot \mathrm{H}_{2} \mathrm{O}$ ), was supplied by Sigma-Aldrich. Methanol (96\%) and all used co-solvents were also purchased from Panreac. The boiling points of the co-solvents were: Acetone $\left(55^{\circ} \mathrm{C}\right)$, DEE $\left(34-35^{\circ} \mathrm{C}\right)$, tBME $\left(55-56{ }^{\circ} \mathrm{C}\right), \operatorname{diIPE}\left(68-69^{\circ} \mathrm{C}\right), \operatorname{diBE}\left(142-143^{\circ} \mathrm{C}\right)$ and $\mathrm{THF}$ $\left(65-67^{\circ} \mathrm{C}\right)$

\subsection{Reaction procedure}

According to the experimental installation used in previous works [20-22], the reactions were carried out in a $1000 \mathrm{~mL}$ spherical reactor, provided with a thermostat, mechanical stirring, sampling outlet and condensation systems. The same amount of oil was used for all experiments ( $250 \mathrm{~g}$ ). Firstly, the oil was placed into the reactor and it was heated up to the reaction temperature. A solution of the established catalyst concentration in methanol was prepared. The desired amount of co-solvent was added to the previous mixture, and the resulting liquid solution was added to the reactor. At spaced intervals, samples were taken out from the reaction mixture and its methyl ester content was determined. Samples and final reaction mixture were placed in separatory funnels to separate the glycerol. Next, the methyl ester phase was heated to remove methanol and co-solvent. Biodiesel was also washed with deionizer water to remove the remaining catalyst. The remaining water was removed by heating at $110^{\circ} \mathrm{C}$.

The studied variables and their intervals of variability were the following: temperature $\left(20,27,30,35\right.$ and $\left.40^{\circ} \mathrm{C}\right)$, agitation rate (500, 700, 900 and $1100 \mathrm{rpm})$, methanol/oil molar ratio (6:1, 9:1 and 12:1), catalyst type (KOH, $\mathrm{Ba}(\mathrm{OH})_{2}, \mathrm{LiOH}, \mathrm{p}-\mathrm{TsOH}, \mathrm{ZnCl}_{2}, \mathrm{AlCl}_{3}$ and $\left.\mathrm{BF}_{3}\right)$, concentration of $\mathrm{KOH}(0.5,0.7$ and $1.0 \mathrm{wt} \%)$, co-solvent type (DEE, tBME, diIPE, diBE, THF and acetone) and methanol/cosolvent molar ratio $(1: 0.5,1: 1,1: 1.5$ and 1:2). Reaction time (120 min), oil type (rapeseed) and alcohol type (methanol) were fixed as common parameters in all experiments.

\subsection{Methods of analysis}

Methyl ester content was determined by means of gas chromatography. A chromatograph Varian 3900 with FID detector and a silica capillary column of $30-\mathrm{m}$ of length, $0.32 \mathrm{~mm}$ of ID and $0.25 \mu \mathrm{m}$ of film thickness, were employed to carry out the analysis. Helium was used as carrier gas. The injector temperature was $270{ }^{\circ} \mathrm{C}$ and the detector temperature, $300^{\circ} \mathrm{C}$. The oven was maintained at $200^{\circ} \mathrm{C}$ for $21 \mathrm{~min}$, then, it was elevated to $220^{\circ} \mathrm{C}$ at $20^{\circ} \mathrm{C} \mathrm{min}^{-1}$ and maintained for $10 \mathrm{~min}$. Internal standard

Table 1

Rapeseed oil fatty acid profile and properties.

\begin{tabular}{ll} 
Fatty acid profile & \\
C16:0 palmitic & $3.5 \%$ \\
C18:0 stearic & $0.9 \%$ \\
C18:1 oleic & $64.4 \%$ \\
C18:2 linoleic & $22.3 \%$ \\
C18:3 linolenic & $8.2 \%$ \\
Density $15^{\circ} \mathrm{C}$ & $906.8 \mathrm{~kg} \mathrm{~m}^{-3}$ \\
Viscosity $40^{\circ} \mathrm{C}$ & $32.0 \mathrm{cSt}$ \\
Iodine value & $112.2 \mathrm{~g}_{\mathrm{I} 2} 100 \mathrm{~g} \mathrm{~g}^{-1}$ \\
Acid value & $2.29 \mathrm{mg}_{\mathrm{KOH}} \mathrm{g}^{-1}$ \\
\hline
\end{tabular}


method was used with methyl heptadecanoate as standard and heptane as solvent.

The rest of properties of biodiesel, such as density, viscosity, water content, saponification, iodine and acid values, flash and combustion points, cold filter plugging point (CFPP) and cetane indexes were determined according to the European Standard UNE-EN 14214 and previous works [22].

\section{Results and discussion}

The transesterification reaction of rapeseed oil in the presence of co-solvents was studied by means of the reactions shown in Table 2 . The values of biodiesel yield, density at $15{ }^{\circ} \mathrm{C}$ and viscosity at $40^{\circ} \mathrm{C}$ for each experiment are also given in the table.

\subsection{Influence of methanol/oil molar ratio}

Methanol/oil molar ratio affects strongly the yield of biodiesel. The stoichiometric methanol/triglycerides molar ratio is $3: 1$. Nevertheless, since transesterification is an equilibrium reaction, excess of alcohol is used in biodiesel production to ensure that oils or fats will be completely converted to esters. Usually there is an optimum of methanol/oil molar ratio, which can be empirically determined. Excessive methanol concentration increases the cost of the alcohol recovery and hinders the separation between biodiesel and glycerol $[23,24]$.

Three experiments (runs 1-3, Table 2) were carried out, varying the molar ratio of methanol to oil from $6: 1$ to $12: 1$. The methyl ester yield, density ${ }_{15}^{\circ} \mathrm{C}$ and viscosity $40^{\circ} \mathrm{C}$ obtained in each experiment are shown in Table 2. The presence of a co-solvent enhances the solubility of the oil in the alcohol, so a reduction of the optimal methanol/oil molar ratio could be expected [16]. However, the results showed that 6:1 was insufficient to reach the highest ester yield. The optimal ratio was 9:1 and the reached biodiesel yield was $93.7 \%$, as it was seen in previous works without co-solvent [22].

Regarding density and viscosity of these samples of biodiesel, they exhibited just slight differences, in accordance with the similarities in the final methyl esters yield.

\subsection{Influence of catalyst concentration}

Catalyst concentration is vital for oil transesterification. Potassium and sodium hydroxides and methoxides showed the highest catalytic activity in transesterification of conventional oils, with typical concentrations from 0.4 to $2 \mathrm{wt} \%$ [9]. Usually, the increase of catalyst amount enhances the reaction rate. However, besides biodiesel production cost, high concentration of catalyst increases the complexity of the product separation because the excess of catalyst could lead to the formation of an emulsion. Therefore, this variable must be suitably optimized.

In this work, the effect of the catalyst concentration in the presence of co-solvent was studied by comparison of the experiments 3-5 and 28 from Table 2. The highest final yield of biodiesel was $97.6 \%$, which was obtained with $0.7 \mathrm{wt} \% \mathrm{KOH}$. The evolution of methyl ester yield for this series of experiments is shown in Fig. 1. As can be seen, the absence of catalyst hindered the formation of methyl esters. This fact was useful to prove that the cosolvent by itself did not prompt to the formation of esters. The methyl ester evolution of a run without co-solvent (run 6, Table 2) was added in Fig. 1 to compare with the rest of reactions of this series. The catalyst concentration for this reaction was $0.7 \mathrm{wt} \%$ $\mathrm{KOH}$; with this amount of catalyst, the presence of co-solvent exercised a positive effect in biodiesel yield. In fact, the maximum yield was obtained operating with co-solvent and with $0.7 \mathrm{wt} \% \mathrm{KOH}$. The use of a suitable concentration of catalyst and co-solvent improved the performance of the transesterification reaction. This behavior was previously observed by other authors using co-solvent [1517].

On the other hand, the differences in density and viscosity were slight. Generally, density and viscosity decreased as ME yield increased. Considering the results obtained in this study, the rest of the experiments were carried out with $0.7 \mathrm{wt} \%$ catalyst concentration.

\subsection{Influence of $\mathrm{MeOH} / \mathrm{Co}$-solvent molar ratio and co-solvent type}

Transesterification reaction is initially heterogeneous due to the poor solubility of the oil in methanol. Then, mass transfer between both phases strongly affects the reaction rate. The use of a cosolvent is an approach to overcome this problem and the amount of co-solvent in the reaction medium will affect biodiesel yield [19]. Therefore, the influence of $\mathrm{MeOH} / \mathrm{co}$-solvent molar ratio was studied varying this parameter in the range 1:0.5-1:2 (runs 5 and 7-9, Table 2). In addition, run 6 was carried out under the same conditions, but without co-solvent, to compare with these runs.

The presence of a little amount of co-solvent allowed an increase of $6.4 \%$ of methyl ester yield. The increase of methanol/ co-solvent molar ratio up to 1:1 led to greater biodiesel yield, probably, because of the lower solubility between methanol and oil at low co-solvent concentrations; as seen by other authors [15,17]. On the other hand, excessive addition of co-solvent could favor the presence of biodiesel and glycerol in the same phase, which could hinder higher final ester yield [15].

Biodiesel yield was just slightly different for the reactions with co-solvent (runs 5 and 7-9), although the results were significantly improved with respect to the absence of co-solvent. These results are qualitatively analogous to the obtained by Mohammed-Dabo et al. [14] in the transesterification of $J$. curcas seed oil, using tetrahydrofuran as co-solvent. In addition, Gupta and Deo [25] found the beneficial effect of the co-solvents in the transesterification with heterogeneous base catalysts. The progress of methyl ester yield in the presence and absence of co-solvent is shown in Fig. 1. As can be seen, both curves showed an initial growing section (30 min), where the positive influence of DEE as co-solvent was clearly noticed. In the last stage of the reaction, methyl ester yield showed asymptotic trend for all reactions.

In addition to DEE other co-solvents were tested (runs 23-27, Table 2). Among them, DEE, tBME and THF showed the highest methyl ester yields, which were greater than $97 \mathrm{wt} \%$. The presence of dilPE, diBE and acetone led to the same result as the yield obtained without co-solvent. Nevertheless, after purification steps, the biodiesel obtained with tBME, diIPE and diBE had strong smell of the co-solvent used in each test.

As shown in materials and methods section, the boiling point of the studied compounds is within a very large temperature range. Methanol, tBE, diIPE, THF and acetone have similar boiling points. For this reason, the removal of them would be easier, but the reuse would be hindered. The maximum boiling point was shown by diBE, which hampered its removal. In contrast, DEE has low boiling point, allowing its rapid elimination and its reuse since its boiling point is much lower than that of methanol. Therefore DEE was the selected co-solvent to carry out most of the experiments which constitute this study.

\subsection{Influence of agitation rate}

Mass transfer limitations are important in transesterification reaction, due to the low solubility between methanol and oil. At the beginning of the reaction, alcohol and oil form a two-phase liq- 
Table 2

Experimental conditions and results.

\begin{tabular}{|c|c|c|c|c|c|c|c|c|}
\hline Run $^{\mathrm{a}}$ & $\mathrm{MeOH} / \mathrm{oil}$ & Catal. (wt\%) & Co-solvent, $\mathrm{MeOH} / \mathrm{C}-\mathrm{S}$ & $T\left({ }^{\circ} \mathrm{C}\right)$ & A.R. (rpm) & ME yield (wt\%) & Dens. $\left(\mathrm{kg} \mathrm{m}^{-3}\right)$ & Visc. (cSt) \\
\hline 1 & $12: 1$ & $\mathrm{KOH}, 1.0$ & DEE, $1: 1$ & 30 & 700 & 91.5 & 874.3 & 4.8 \\
\hline 2 & $6: 1$ & $\mathrm{KOH}, 1.0$ & DEE, $1: 1$ & 30 & 700 & 87.6 & 873.2 & 5.0 \\
\hline 3 & $9: 1$ & $\mathrm{KOH}, 1.0$ & DEE, $1: 1$ & 30 & 700 & 93.7 & 875.1 & 4.6 \\
\hline 4 & $9: 1$ & $\mathrm{KOH}, 0.5$ & DEE, $1: 1$ & 30 & 700 & 91.2 & 874.7 & 5.0 \\
\hline 5 & $9: 1$ & $\mathrm{KOH}, 0.7$ & DEE, $1: 1$ & 30 & 700 & 97.6 & 868.6 & 4.5 \\
\hline 6 & $9: 1$ & $\mathrm{KOH}, 0.7$ & None & 30 & 700 & 89.8 & 873.6 & 5.1 \\
\hline 7 & $9: 1$ & $\mathrm{KOH}, 0.7$ & DEE, 1:0.5 & 30 & 700 & 96.2 & 868.6 & 4.6 \\
\hline 8 & $9: 1$ & $\mathrm{KOH}, 0.7$ & DEE, $1: 1.5$ & 30 & 700 & 96.0 & 872.9 & 4.8 \\
\hline 9 & $9: 1$ & $\mathrm{KOH}, 0.7$ & DEE, $1: 2$ & 30 & 700 & 93.9 & 867.8 & 4.9 \\
\hline 10 & $9: 1$ & $\mathrm{KOH}, 0.7$ & DEE, $1: 1$ & 30 & 500 & 96.5 & 869.3 & 4.6 \\
\hline 11 & $9: 1$ & $\mathrm{KOH}, 0.7$ & DEE, $1: 1$ & 30 & 900 & 95.1 & 877.0 & 4.6 \\
\hline 12 & $9: 1$ & $\mathrm{KOH}, 0.7$ & DEE, $1: 1$ & 30 & 1100 & 96.7 & 874.7 & 4.6 \\
\hline 13 & $9: 1$ & $\mathrm{KOH}, 0.7$ & DEE, $1: 1$ & 40 & 700 & 96.2 & 876.4 & 4.6 \\
\hline 14 & $9: 1$ & $\mathrm{KOH}, 0.7$ & DEE, $1: 1$ & 35 & 700 & 96.4 & 867.6 & 4.6 \\
\hline 15 & $9: 1$ & $\mathrm{KOH}, 0.7$ & DEE, $1: 1$ & 27 & 700 & 97.6 & 871.0 & 4.9 \\
\hline 16 & $9: 1$ & $\mathrm{KOH}, 0.7$ & DEE, $1: 1$ & 20 & 700 & 96.2 & 870.7 & 4.8 \\
\hline 17 & $9: 1$ & $\mathrm{Ba}(\mathrm{OH})_{2}, 0.7$ & DEE, $1: 1$ & 30 & 700 & 76.8 & 879.4 & 6.7 \\
\hline 18 & $9: 1$ & $\mathrm{LiOH}, 0.7$ & DEE, $1: 1$ & 30 & 700 & 96.8 & 870.8 & 4.7 \\
\hline 19 & $9: 1$ & $p$-TsOH, 0.7 & DEE, $1: 1$ & 30 & 700 & - & - & - \\
\hline 20 & $9: 1$ & $\mathrm{ZnCl}_{2}, 0.7$ & DEE, $1: 1$ & 30 & 700 & - & - & - \\
\hline 21 & $9: 1$ & $\mathrm{AlCl}_{3}, 0.7$ & DEE, $1: 1$ & 30 & 700 & - & - & - \\
\hline 22 & $9: 1$ & $\mathrm{BF}_{3}, 0.7$ & DEE, $1: 1$ & 30 & 700 & - & - & - \\
\hline 23 & $9: 1$ & $\mathrm{KOH}, 0.7$ & tBME, $1: 1$ & 30 & 700 & 97.5 & 869.0 & 4.6 \\
\hline 24 & $9: 1$ & $\mathrm{KOH}, 0.7$ & diIPE, $1: 1$ & 30 & 700 & 89.5 & 871.8 & 5.0 \\
\hline 25 & $9: 1$ & $\mathrm{KOH}, 0.7$ & diBE, $1: 1$ & 30 & 700 & 74.3 & 844.6 & 3.0 \\
\hline 26 & $9: 1$ & $\mathrm{KOH}, 0.7$ & THF, $1: 1$ & 30 & 700 & 98.3 & 862.3 & 4.6 \\
\hline 27 & $9: 1$ & $\mathrm{KOH}, 0.7$ & Acetone, $1: 1$ & 30 & 700 & 89.3 & 870.3 & 4.8 \\
\hline 28 & $9: 1$ & None & DEE, $1: 1$ & 30 & 700 & - & - & - \\
\hline
\end{tabular}

${ }^{a} \mathrm{MeOH} /$ oil: methanol/oil molar ratio; Catal., wt\%: catalyst and its amount; Co-solvent, MeOH/C-S: co-solvent and methanol/co-solvent molar ratio; T.: reaction temperature; A.R.: agitation rate; ME yield: methyl ester yield; Dens.: biodiesel density at $15^{\circ} \mathrm{C}$; Visc.: biodiesel viscosity at $40{ }^{\circ} \mathrm{C}$.

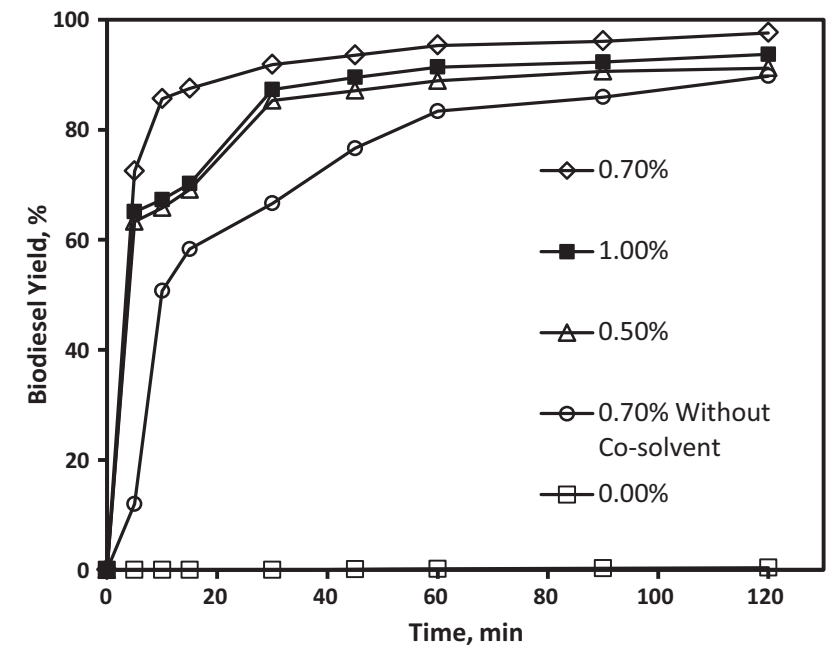

Fig. 1. Biodiesel yield. Influence of catalyst concentration.

uid system; the reaction is diffusion-controlled, resulting in slow rate. Although as methyl esters are formed, they act as a mutual solvent for the reagents, it is necessary to stir the mixture to achieve suitable reaction rate.

In this section, the influence of agitation rate on biodiesel yield was studied in the range 500-1100 rpm (runs 5, 10-12, Table 2). As can be seen in Table 2, even with a wide range of agitation rate, the influence of this parameter was little significant with methyl ester yield values between 95.1 and $97.6 \mathrm{wt} \%$. Agitation rate would have an important effect during the first stage of the reaction, but the presence of a co-solvent enhanced the solubility between the reagents. This contributed to speed up the reaction and agitation rate had slight effect on the results, as seen in previous works [13-19].

\subsection{Influence of reaction temperature}

Temperature is a variable that exerts great influence on reaction rate and biodiesel yield [24]. This variable affects kinetics and equilibrium constants of the reaction system. Additionally, high temperatures decrease the viscosity of oil and improve mass transfer and reactivity between the reagents. But also, temperature promotes the triglycerides saponification reaction and decreases the biodiesel yield. In addition, the reaction temperature will be lower than the boiling point of methanol and co-solvent in order to avoid the vaporization of these components.

Tests with reaction temperatures between 20 and $40{ }^{\circ} \mathrm{C}$ were carried out (runs 5, 13-16, Table 2). These temperatures were lower than the boiling point of methanol and, in general, lower

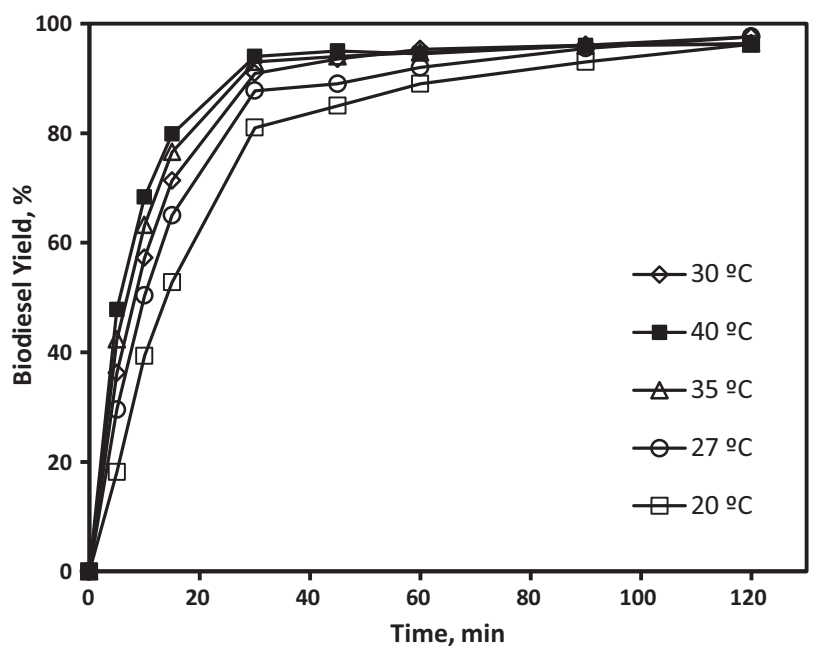

Fig. 2. Biodiesel yield. Influence of reaction temperature. 
than the boiling point of DEE. Fig. 2 shows the evolution of the biodiesel yield for this group of reactions.

High biodiesel conversions were obtained in all cases. Specifically, in the experiment carried out at room temperature $\left(T_{\text {room }}=20^{\circ} \mathrm{C}\right)$, a biodiesel yield of $96.3 \%$ was obtained. From an economical point of view, this fact would allow the reduction of process costs. The reaction temperature showed positive influence during the first minutes of reaction, after that the final biodiesel yield was similar for all reactions. The same effect could be seen for other type of oils and co-solvents in previous works [15,17]. Moreover, an increase in temperature would lead to DEE evaporation, higher energy consumption and soap formation [24]. For these reasons, $30^{\circ} \mathrm{C}$ (close to room temperature) was considered as the optimum temperature for this reaction.

\subsection{Transesterification reaction with other catalysts}

The use of co-solvent improved the reaction rate when $\mathrm{KOH}$ was used as catalyst. Other catalysts are known as less effective catalysts under other conditions [26]. In this work several reactions with another kind of catalysts were carried out in order to test if the presence of a co-solvent could increase its efficiency until $\mathrm{KOH}$ activity. In order to achieve this aim, $\mathrm{Ba}(\mathrm{OH})_{2}$ and $\mathrm{LiOH}$ were used as alkaline catalysts and $\mathrm{AlCl}_{3}, \mathrm{ZnCl}_{2}, \mathrm{BF}_{3}$ and $p$ toluenesulfonic acid as acid catalysts (runs 17-22 from Table 2). The acid catalysts showed very little activity, since after $120 \mathrm{~min}$ of reaction, at $30^{\circ} \mathrm{C}$ and $700 \mathrm{rpm}$, the conversion was null in all cases. Probably, the experimental conditions $(0.7 \mathrm{wt} \%$ catalyst, 9:1 MeOH/oil, 1:1 MeOH/DEE) were too soft and more drastic conditions would be necessary. Guan et al. [27] achieved the transesterification of corn oil, using $4 \mathrm{wt} \% \mathrm{p}$-TsOH in the presence of DEE, at $80{ }^{\circ} \mathrm{C}$ and $500 \mathrm{kPa}$. On the other hand, Soriano et al. [28] used THF as co-solvent for the transesterification of canola oil with $5 \mathrm{wt} \% \mathrm{AlCl}_{3}, 24: 1$ of methanol/oil molar ratio, at $110^{\circ} \mathrm{C}$ and they needed $18 \mathrm{~h}$ to reach high conversion.

The alkaline catalysts were more effective. Conversions of $96.8 \%$ and $76.9 \%$ were obtained with $\mathrm{LiOH}$ and $\mathrm{Ba}(\mathrm{OH})_{2}$, respectively. So, the presence of DEE allowed that $\mathrm{KOH}$ and $\mathrm{LiOH}$ showed almost the same activity, while $\mathrm{KOH}$ had shown better results under other conditions, such as under methanol subcritical conditions [26]. However, the purification of biodiesel was a slow and difficult process with $\mathrm{Ba}(\mathrm{OH})_{2}$ and $\mathrm{LiOH}$. Hence, Li and Ba catalysts, along with DEE as co-solvent, do not improve the results obtained with $\mathrm{KOH}$.

\subsection{Kinetic and thermodynamic analysis}

Transesterification reaction occurs through three consecutive and reversible reactions. The first step is the reaction between one molecule of triglyceride (TG) and methanol to produce a diglyceride (DG) and one molecule of methyl ester (FAME). The obtained diglyceride reacts with methanol to form a monoglyceride (MG) and another molecule of FAME. In the final step, MG reacts with methanol to yield the third molecule of FAME and one molecule of glycerol. Thus three molecules of FAME and one molecule of glycerol are formed by the completion of the reaction. According to generalized tendencies in literature [29], the kinetic constant of the global reaction, without considering intermediate steps, will be determined in this work. Under these conditions, the simplest kinetic model which fitted suitably the data was the pseudo first-order kinetic model. The used equation was:

$\ln (1-X)=-k t$

where $X$ is the conversion of TG at any time $t$, and $k$ is the rate constant. By plotting $-\ln (1-X)$ versus time, $k$ was obtained from the slope of the curve.
The kinetics of the transesterification reaction was studied at five temperatures between 20 and $40{ }^{\circ} \mathrm{C}$ (runs 5, 13-16, Table 2 and Fig. 2). The graphical representation of Eq. (1) corresponding to each reaction is reported in Fig. 3. As can be seen, experimental data showed linear trend during the first 30 min of reaction. For longer times, the conversion values remained practically constant (asymptotic zone), and experimental points did not showed the same linear trend.

The regression analysis of the data plotted in Fig. 3 was collected in Table 3, where pseudo kinetic constants and $R^{2}$ coefficient are provided. The high values of $R^{2}$ confirm that this system follows a pseudo first-order kinetic model.

The relationship among specific reaction rate constant $(k)$, absolute temperature $(T)$ and activation energy $\left(E_{a}\right)$ is given by Arrhenius Eq. (2), where $A$ is the frequency factor and $R$ is the universal gas constant:

$k=A \exp \left(-E_{a} / R T\right)$

Experiments 5 and 13-16 (Table 2) were considered again to determine the activation energy. Eq. (2) could be linearized as shown in Fig. 4. From the slope of the curve, the activation energy was determined; its value was $21.88 \mathrm{~kJ} \mathrm{~mol}^{-1}$. This value was relatively small, which reveals great catalytic activity of basic catalysts $(\mathrm{KOH})$.

Thermodynamic characteristics of the transesterification reaction were calculated based on the rate constants. Eyring-Polanyi equation was used (3), where $k$ is the rate constant at temperature $T$, and $\Delta H$ and $\Delta S$ are the changes in enthalpy and entropy of activation for the reaction system, respectively. On the other hand, $k_{b}$, $h$ and $R$ are Boltzmann, Planck, and universal gas constant, respectively.

$\ln (k / T)=-\Delta H / R T+\ln \left(k_{b} / h\right)+\Delta S / R$

The Eyring-Polanyi plot for the transesterification reaction is shown in Fig. 5. $\Delta H$ and $\Delta S$ were determined from the slope and $y$-intercept of the Eyring-Polanyi plot. Table 4 lists the value of $\Delta H, \Delta S$ and $\Delta G$ (Gibbs energy change) for transesterification reaction; the last parameter was determined by the equation $\Delta G=\Delta H-T \Delta S$.

\subsection{Fuel specifications}

In addition to Table 2, in Table 5 other important parameters for some of the experiments together with the standard are shown.

Biodiesel density and viscosity are directly related to the engine performance $[30,31]$. The established values by EN-14214 are

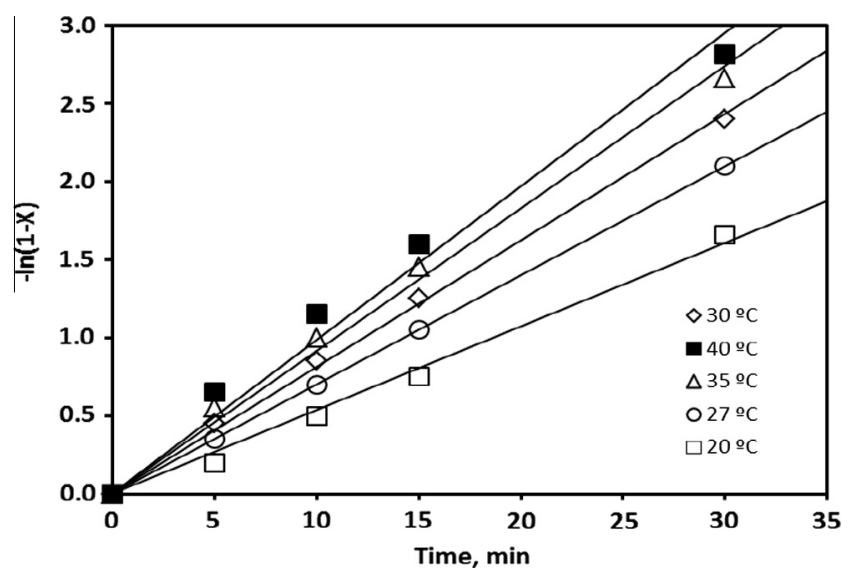

Fig. 3. Determination of kinetic constants according to pseudo first-order kinetic model. 
Table 3

Kinetic analysis of transesterification process.

\begin{tabular}{lll}
\hline Temperature $(\mathrm{K})$ & Pseudo first-order kinetics $\left(\mathrm{min}^{-1}\right)$ & $R^{2}$ \\
\hline 293 & 0.0537 & 0.99 \\
300 & 0.070 & 0.99 \\
303 & 0.081 & 0.99 \\
308 & 0.0914 & 0.98 \\
313 & 0.0985 & 0.98
\end{tabular}

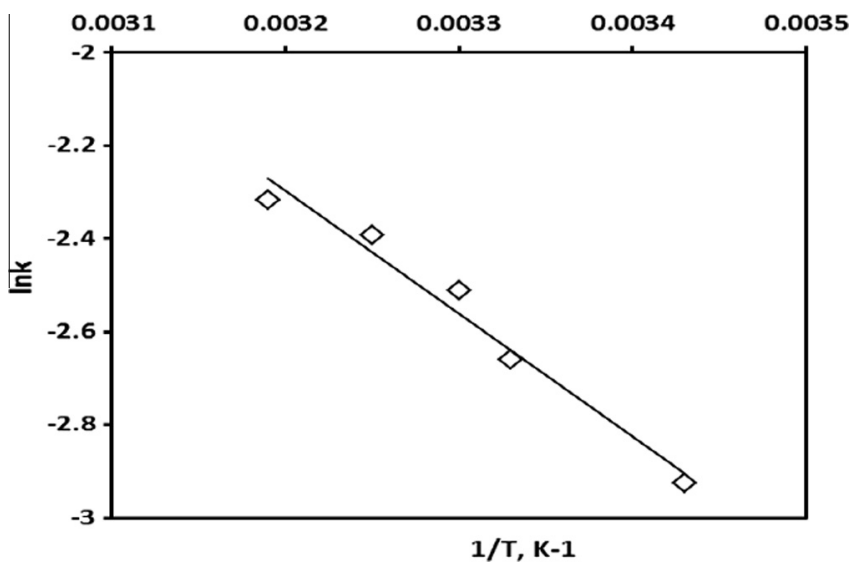

Fig. 4. Arrhenius plot. Activation energy determination for transesterification process (best fit: $\ln k=-2634.8 / T+6.134 ; R^{2}=0.97$ ).

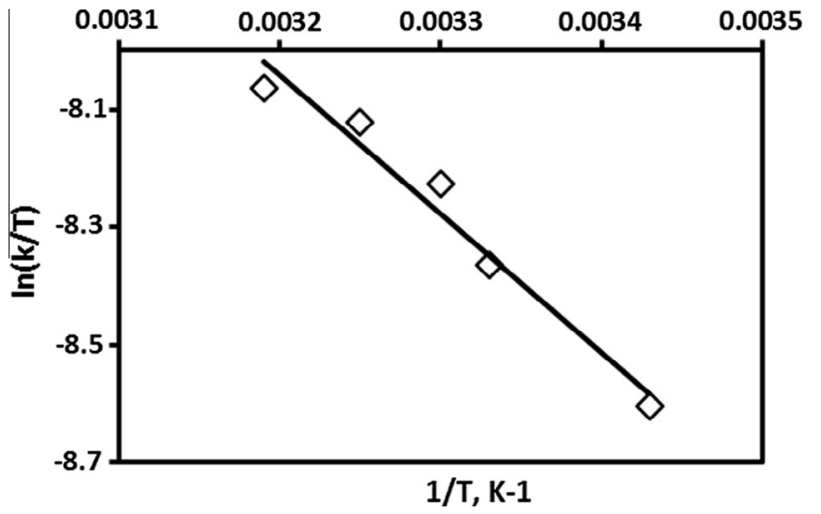

Fig. 5. Eyring-Polanyi plot. Determination of the variations of enthalpy and entropy of activation during the reaction of transesterification. Best fit: $\ln (k / T)=-2356.5$ / $T-0.5$.

$860-900 \mathrm{~kg} \mathrm{~m}^{-3}$ and $3.5-5.0 \mathrm{cSt}$ for density ${ }_{15^{\circ} \mathrm{C}}$ and viscosity $40^{\circ} \mathrm{C}$ of biodiesel, respectively. As seen in Table 2, density values were mainly between 862.3 and $879.4 \mathrm{~kg} \mathrm{~m}^{-3}$, which are within the European regulation. In addition, this parameter remained
Table 4

Thermodynamic analysis of transesterification process.

\begin{tabular}{llll}
\hline Temperature $(\mathrm{K})$ & $\Delta H\left(\mathrm{~kJ} \mathrm{~mol}^{-1}\right)$ & $\Delta S\left(\mathrm{~kJ} \mathrm{~mol}^{-1} \mathrm{~K}^{-1}\right)$ & $\Delta G\left(\mathrm{~kJ} \mathrm{~mol}^{-1}\right)$ \\
\hline 293 & 19.59 & -0.19 & 75.26 \\
300 & & & 76.59 \\
303 & & 77.16 \\
308 & & 78.11 \\
313 & & 79.06
\end{tabular}

practically constant at different ester content. On the other hand viscosity considerably depends on ester content. In this work, the only viscosity value higher than the range showed low ester content (run 17). The experiment 25 (with di-n-butyl ether as co-solvent) had lower density and viscosity than the limits given by the regulation, which could be explained by the presence of co-solvent. This biodiesel also showed unusual values for the rest of parameters (Table 5 ).

According to Table 5, the content in water exceeds, in general, the stated value for the standard. The presence of water in biodiesel fuels could cause engine corrosion, although this content depends strongly on the storage step [32]. Saponification values ranged from 167.5 to $183.8 \mathrm{mg}$ of $\mathrm{KOH}$ per gram of sample. This value and iodine value are related to the fatty acid profile; that is the raw material. In consequence, there are not significant variations of these properties for the evaluated samples. Iodine values, which show the degree of fuel unsaturation, were enclosed between 106.8 and $119.0 \mathrm{~g}_{\mathrm{I} 2} 100 \mathrm{~g}^{-1}$, in any case, it was smaller than the maximum established by the regulation EN-14214 $\left(120 \mathrm{~g}_{\mathrm{I} 2} 100 \mathrm{~g}^{-1}\right)$. On the other hand, acid value is a measure of the free fatty acid level in biodiesel. In general, the acid value of the samples was in accordance with the maximum required limit $\left(<0.5 \mathrm{mg}_{\mathrm{KOH}} \mathrm{g}^{-1}\right)$, except for biodiesel 17 and 25 , which showed low methyl ester yield.

Cold filter plugging point (CFPP) reflects the cold weather performance of a fuel. At low operating temperature, fuel might thicken and not flow properly affecting the performance of fuel lines, fuel pumps and injectors [33]. In EN-14214 the CFPP value is not specified, since it is different at each country; however, the biodiesel from runs 24 to 27 could not be used due to their high CFPP value. Flash point is a measure of the flammability of fuels and thus an important parameter for assessing hazards during fuel transport and storage [34]. The flash point of the biodiesel is higher than that of diesel oil, which is safer for transport. The flash points shown in Table 5 were enclosed between 167.8 and $192.0^{\circ} \mathrm{C}$. Hence, in all cases they were above the minimum value established by the standard EN-14214. Combustion point is not regulated in the standard. The biodiesel samples had a combustion point above $185^{\circ} \mathrm{C}$, compared to $95^{\circ} \mathrm{C}$, typical of diesel No. 2, this biodiesel has a guarantee security [20].

One of the most important measures of ignition characteristics of diesel and/or biodiesel fuels is cetane number, which is a dimensionless descriptor for the ignition delay time of a diesel fuel upon

Table 5

Parameters of biodiesel characterization.

\begin{tabular}{|c|c|c|c|c|c|c|c|c|c|c|c|}
\hline \multirow{2}{*}{\multicolumn{2}{|c|}{ Parameter }} & \multicolumn{9}{|l|}{ Run } & \multirow[t]{2}{*}{ EN-14214 } \\
\hline & & 5 & 6 & 17 & 18 & 23 & 24 & 25 & 26 & 27 & \\
\hline \multicolumn{2}{|l|}{ Water content (\%) } & 0.07 & 0.07 & 0.13 & 0.09 & 0.04 & 0.05 & 0.08 & 0.07 & 0.06 & $<0.05$ \\
\hline \multicolumn{2}{|c|}{ Saponification value $\left(\mathrm{mg}_{\text {кон }} \mathrm{g}^{-1}\right)$} & 174.4 & 170.3 & 180.7 & 183.8 & 168.0 & 168.4 & 127.7 & 167.5 & 175.0 & - \\
\hline \multicolumn{2}{|c|}{ Iodine value $\left(\mathrm{g}_{\mathrm{I} 2} 100 \mathrm{~g}^{-1}\right)$} & 111.9 & 119.0 & 106.8 & 112.3 & 114.6 & 111.6 & 91.8 & 115.3 & 118.4 & $\leqslant 120$ \\
\hline \multicolumn{2}{|l|}{ Acid value $\left(\mathrm{mg}_{\mathrm{\kappa он}} \mathrm{g}^{-1}\right)$} & 0.23 & 0.13 & 0.75 & 0.20 & 0.21 & 0.19 & 0.69 & 0.34 & 0.27 & $\leqslant 0.5$ \\
\hline \multicolumn{2}{|l|}{ CFPP $\left({ }^{\circ} \mathrm{C}\right)$} & -2 & -4 & -1 & - & -1 & 7 & 3 & 6 & 10 & \\
\hline \multicolumn{2}{|l|}{ Flash point $\left({ }^{\circ} \mathrm{C}\right)$} & 178.0 & 187.0 & 183.8 & - & 183.0 & 192.0 & - & 167.8 & 182.0 & $\geqslant 120$ \\
\hline \multicolumn{2}{|l|}{ Combustion point $\left({ }^{\circ} \mathrm{C}\right)$} & 191.5 & 195.0 & 194.0 & - & 193.1 & 178.0 & 65.0 & 185.0 & 191.0 & - \\
\hline \multirow{2}{*}{\multicolumn{2}{|c|}{ Cetane index }} & 41.3 & 44.0 & - & - & 38.1 & 44.4 & & 45.8 & - & \\
\hline & Eqs. (4) and (6) & 54.8 & 55.1 & 55.3 & 55.4 & 54.9 & 54.6 & 54.8 & 54.8 & 54.9 & $>51$ \\
\hline Estimated cetane number & Eqs. (5) and (6) & 56.4 & 56.6 & 56.7 & 56.8 & 56.4 & 56.1 & 56.4 & 56.4 & 56.4 & $>51$ \\
\hline
\end{tabular}


Table 6

Cetane number estimated for the fatty acid esters (CNME).

\begin{tabular}{lll}
\hline FAME $(\mathrm{Cn}: \mathrm{db})$ & $\mathrm{CN}_{\mathrm{ME}}$ by Eq. (4) & $\mathrm{CN}_{\mathrm{ME}}$ by Eq. (5) \\
\hline Palmitate (16:0) & 73.9 & 80.4 \\
Palmitoleate (16:1) & 53.3 & 55.0 \\
Stearate $(18: 0)$ & 82.3 & 89.3 \\
Oleate $(18: 1)$ & 61.7 & 61.6 \\
Linoleate $(18: 2)$ & 41.1 & 43.3 \\
Linolenate (18:3) & 20.5 & 31.2 \\
Erucate $(22: 1)$ & 78.7 & 73.3 \\
\hline
\end{tabular}

injection into the combustion chamber [34,35]. Cetane index is a calculated quantity that is intended to approximate cetane number. In general, as seen in Table 5 , the values of cetane index are very similar and ranged from 38.1 to 45.8 . On the other hand, according to the standards EN-14214 and EN-590, cetane number must be greater than 51 . But its determination is a high cost method and can show reproducibility errors; so, some correlations were used in order to estimate the cetane number. Firstly, the cetane number of each fatty acid methyl ester (FAME) were estimated, using other properties, according to Eqs. (4) and (5) proposed by Ramírez-Verduzco and Lapuerta [36,37], respectively.

$\mathrm{CN}_{\mathrm{ME}}=-7.8+0.302 M_{i}-20 \mathrm{db}$

$\mathrm{CN}_{\mathrm{ME}}=-23.523+\left(2.366+6.299 e^{-0.411 \mathrm{db}}\right) C_{n} e^{-0.818 \mathrm{Cn}}$

where $\mathrm{CN}_{\mathrm{ME}}$ represents cetane number for fatty acid esters, $M_{i}$ the molecular weight of the $i$ th FAME, $\mathrm{db}$ is the number of double bonds in a given FAME and $C_{n}$ the number or carbon atoms in the original fatty acid.

Assuming that the mixture (biodiesel) behaves optimally with respect to cetane number, this can be obtained by Eq. (6).

$f_{b}=\Sigma^{n} z_{i} f_{i}$

where $f$ is a function that represents any physical property of biodiesel (b) and pure FAME (i); $z_{i}$ is the mass or mole fraction of the ith FAME.

Table 6 shows the cetane number for fatty acid esters $\left(\mathrm{CN}_{\mathrm{ME}}\right)$, estimated with the correlations given by Eqs. (4) and (5). The estimated values by means of both equations are very similar, although the estimates by means of Eq. (5) are lightly bigger. Taking into account the ME distribution of the different biodiesel samples, the estimated $\mathrm{CN}_{\mathrm{ME}}$ and Eq. (6), the biodiesel cetane number $\left(\mathrm{CN}_{\text {bio }}\right)$ was estimated; the results are given in Table 5. As can be seen, the estimated values for these biodiesel samples are higher than the value demanded by the standard EN-14214 (>51.0). In consequence, in reference to this parameter, the synthesized biodiesel achieved the recommendations of the standard EN-14214.

\section{Conclusions}

The use of co-solvent improves the mass transfer between the phases present in the transesterification process. Therefore, high biodiesel yield can be achieved in small reaction times, even at room temperature. The most effective co-solvents were DEE and THF. The first one can be considered as an excellent low-polar solvent that can increase the mutual solubility of oil and methanol. The THF originated similar conversions to the obtained with DEE, but the recuperation of this co-solvent was more difficult in comparison to that of DEE.

After studying the effect of catalyst type and concentration, methanol/oil molar ratio, methanol/co-solvent molar ratio, agitation rate and reaction temperature, the highest methyl ester yields, 97-98\%, were achieved with $0.7 \mathrm{wt} \% \mathrm{KOH}, 9: 1$ as methanol/oil molar ratio, 1:1 as co-solvent/methanol molar ratio, $700 \mathrm{rpm}$ and $30{ }^{\circ} \mathrm{C}$. Transesterification reaction followed a kinetic model of pseudo-first order and the rate constants at several temperatures were determined. Also, activation energy and the variations of enthalpy and entropy for the system of reaction were determined by means of application of Arrhenius and Eyring Polanyi equations, as a useful tool for future works. Finally, all samples of biodiesel were characterized and the ones with the highest ester contents showed only limitation on water content.

\section{Acknowledgements}

The authors express their gratitude to the "MICINN" and the "Junta de Extremadura" for the financial support received to perform this study by means of Projects ENE2009-13881 and PRI09B102, respectively. JM Encinar thanks the privilege that supposed in his life the participation in the project carried out by the Five and Company group. N Sánchez thanks Ministry of Education from Spain for FPU Grant received.

\section{References}

[1] EC. Directive 2003/30/EC of the European Parliament and the Council of May 8; 2003.

[2] Atabani AE, Silitonga AS, Badruddin IA, Mahlia TMI, Masjuki HH, Mekhilef S. A comprehensive review on biodiesel as an alternative energy resource and its characteristics. Renew Sust Energy Rev 2012;16:2070-93.

[3] Chattopadhyay S, Sen R. Fuel properties, engine performance and environmental benefits of biodiesel produced by a green process. Appl Energy 2013:105:319-26.

[4] Murugesan A, Umarani C, Subramanian R, Nedunchezhian N. Bio-diesel as an alternative fuel for diesel engines - a review. Renew Sust Energy Rev 2009;13:653-62.

[5] Bozbas K. Biodiesel as an alternative motor fuel: production and policies in the European Union. Renew Sust Energy Rev 2008;12:542-52.

[6] Vyas AP, Verma JL, Subrahmanyam N. A review on FAME production processes. Fuel 2010;89:1-9.

[7] Xue J, Grift TE, Hansen AC. Effect of biodiesel on engine performances and emissions. Renew Sust Energy Rev 2011;15:1098-116.

[8] Balat M, Balat $H$. Progress in biodiesel processing. Appl Energy 2010:87:1815-35.

[9] Meher LC, Vidya Sagar D, Naik SN. Technical aspects of biodiesel production by transesterification - a review. Renew Sust Energy Rev 2006;10:248-68.

[10] Li Y, Qiu F, Yang D, Sun P, Li X. Transesterification of soybean oil and analysis of bioproduct. Food Bioprod Process 2012;90:135-40.

[11] Ma F, Clements LD, Hanna MA. Biodiesel fuel from animal fat. Ancillary studies on transesterification of beef tallow. Ind Eng Chem Res 1998:90:135-40.

[12] Muppaneni T, Reddy HK, Patil PD, Dailey P, Aday C, Deng S. Ethanolysis of camelina oil under supercritical condition with hexane as a co-solvent. Appl Energy 2012;94:84-8.

[13] Boocock DGB, Konar SK, Mao V, Sidi H. Fast one-phase oil-rich processes for the preparation of vegetable oil methyl esters. Biomass Bioenergy 1996;11:43-50.

[14] Mohammed-Dabo IA, Ahmad MS, Hamza A, Muazu K, Aliyu A. Cosolvent transesterification of Jatropha curcas seed oil. J Petrol Technol Altern Fuel $2012 ; 3: 42-51$

[15] Thanh LT, Okitsu K, Sadanaga Y, Takenaka N, Maeda Y. A new co-solvent method for the green production of biodiesel fuel - optimization and practical application. Fuel 2013;103:742-8.

[16] Luu PD, Takenaka N, Van Luu B, Pham LN, Imamura K, Maeda Y. Co-solvent method produce biodiesel form waste cooking oil with small pilot plant. Energy Procedia 2014;61:2822-32.

[17] Alhassan Y, Kumar N, Bugaje IM, Pali HS, Kathkar P. Co-solvents transesterification of cotton seed oil into biodiesel: effects of reaction conditions on quality of fatty acids methyl esters. Energy Convers Manage 2014;84:640-8.

[18] Casas A, Fernández CM, Ramos MJ, Pérez Á, Rodríguez JF. Optimization of the reaction parameters for fast pseudo single-phase transesterification of sunflower oil. Fuel 2010;89:650-8.

[19] Abbaszaadeh A, Ghobadian B, Omidkhah MR, Najafi G. Current biodiesel production technologies: a comparative review. Energy Convers Manage 2012:63:138-48.

[20] Encinar JM, González JF, Rodríguez-Reinares A. Ethanolysis of used frying oil. Biodiesel preparation and characterization. Fuel Proc Technol 2007:88:513-22.

[21] Encinar JM, Sánchez N, Martínez G, García L. Study of biodiesel production from animal fats with high free fatty acid content. Bioresource Technol 2011;102:10907-14

[22] Martínez G, Sánchez N, Encinar JM, González JF. Fuel properties of biodiesel from vegetable oils and oil mixtures. Influence of methyl esters distribution. Biomass Bioenergy 2014;63:22-32. 
[23] Ma F, Hanna MA. Biodiesel production: a review. Bioresour Technol 1999; $70: 1-15$

[24] Leung DYC, Wu X, Leung MKH. A review on biodiesel production using catalyzed transesterification. Appl Energy 2010;87:1083-95.

[25] Gupta AK, Deo G. Biodiesel production by transesterification using heterogeneous base catalyst and effect of co-solvent. In: $11 \mathrm{AiChE}$ annual meeting, catalysis and reaction engineering division; 2011. 726f.

[26] Encinar JM, Pardal A, Martínez G. Transesterification of rapeseed oil in subcritical methanol conditions. Fuel Process Technol 2012;94:40-6.

[27] Guan G, Kusakabe K, Sakurai N, Moriyama K. Transesterification of vegetable oil to biodiesel fuel using acid catalysts in the presence of dimethyl ether. Fuel 2009;88:81-6.

[28] Soriano Jr NU, Venditti R, Argyropoulos DS. Biodiesel synthesis via homogeneous Lewis acid-catalyzed transesterification. Fuel 2009;88: $560-5$.

[29] Choudhury HA, Srivastava P, Moholkar VS. Single-step ultrasonic synthesis of biodiesel from crude Jatropha curcas oil. AIChE J 2014;60:1572-81.

[30] Dzida M, Prusakiewicz P. The effect of temperature and pressure on the physicochemical properties of petroleum diesel oil and biodiesel fuel. Fuel 2008;87:1941-8.
[31] Tate RE, Watts KC, Allen CAW, Wilkie KI. The viscosities of three biodiesel fuels at temperatures up to $300{ }^{\circ} \mathrm{C}$. Fuel 2006;85:1010-5.

[32] Peña R, Romero R, Martínez SL, Ramos MJ, Martínez A, Natividad R. Transesterification of Castor Oil: effect of catalyst and co-solvent. Ind Eng Chem Res 2009;48:1186-9.

[33] Enweremadu CC, Mbarawa MM. Technical aspects of production and analysis of biodiesel from used cooking oil - a review. Renew Sust Energy Rev 2009;13:2205-24.

[34] Van Gerpen J, Shanks B, Pruszko R, Clements D, Knothe G. Biodiesel analytical methods. Colorado: National Renewable Energy Laboratory; 2004.

[35] Knothe G, Matheaus AC, Ryan TW. Cetane numbers of branched and straightchain fatty esters determined in an ignition quality tester. Fuel 2003;82:971-5.

[36] Ramírez-Verduzco LF, Rodríguez-Rodríguez JE, del Rayo Jaramillo-Jacob A. Predicting cetane number, kinematic viscosity, density and higher heating value of biodiesel from its fatty acid methyl ester composition. Fuel 2012;91:102-11.

[37] Lapuerta M, Rodríguez-Fernández J, Armas O. Correlation for the estimation of the density of fatty acid esters fuels and its implications. A proposed biodiesel cetane index. Chem Phys Lipids 2010;163:720-7. 